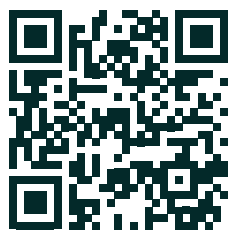

\title{
Broyler Ebeveyn Kuluçkalık Yumurtalarına In Ovo Bes- leme Yöntemi İle Propolis Ekstraktı Enjeksiyonunun Kuluçka Sonuçlarına Etkileri
}

\section{The effects of in ovo injection of propolis solution to broiler hatching eggs on incubation results}

\section{Hikmet TEBER ${ }^{1}$}

\section{İskender YILDIRIM ${ }^{2}$}

${ }^{1}$ Selçuk Üniversitesi, Fen Bilimleri Enstitüsü, Selçuklu, Konya

${ }^{2}$ Selçuk Üniversitesi, Ziraat Fakültesi, Selçuklu, Konya

Sorumlu yazar: iyildir@selcuk.edu.tr

ORCID (Yazar Sırasına Göre):

0000-0002-6196-1839

iD $0000-0002-1818-2856$

Gönderilme Tarihi : 16 Ocak 2020

Kabul Tarihi $\quad$ : 10 Mart 2020

* İlgili çalışma Hikmet Teber'in Yüksek Lisans çalışmasının bir parçası olup, özeti 4.Ulusal Tarım Kongresinde yayınlanmıştır.

Destekleyen Kurum: S.Ü. BAP Koordinatörlüğü Proje Numarası : : 15201082

\section{ÖZET}

$\mathrm{Bu}$ çalışma, broyler ebeveynlerinden elde edilen kuluçkalık yumurtalara amniyon sivisina in ovo besleme yöntemi ile propolis ekstraktı enjeksiyonunun kuluçka sonuçlarına etkilerini belirlemek amaciyla yürütülmüştür. Denemede toplam 500 adet Ross 308 adet broyler ebeveyn yumurtas kullanılmıştır. Araştırmanın deneme deseni; Negatif kontrol grubu (in ovo uygulama yok), Pozitif kontrol grubu $(0.5 \mathrm{~mL}$ alkol çözeltisi/yumurta), Propolis 1 (P1) grubu (0.5 mL \%5' lik P1 çözeltisi/yumurta), Propolis 2 (P2) grubu $(0.5 \mathrm{~mL}$ \%10’ luk P2 çözeltisi/yumurta), Propolis 3 (P3) grubu (0.5 mL \%15’ lik P3 çözeltisi/yumurta), olmak üzere beş gruptan oluşmuştur. Uygulama, kuluçkanın 18. gününde in ovo besleme solüsyonlarının her bir muamele grubu için $0.5 \mathrm{ml}$ ' lik dozlarda amniyon sıvısı içerisine enjeksiyonu şeklinde gerçekleştirilmiştir.

Çalışmada in ovo propolis enjeksiyonunun çıkış gücü, iç 
pip, dış pip ve toplam ölüm oranlarını olumsuz etkilediği görülmüştür. Tepside ölüm oranı bakımından muamele grupları arasındaki farklılıklar ise istatistiki olarak önemsiz bulunmuştur. Çalışmanın değişik çözücülerin kullanıldı̆̆ı propolis örnekleri veya dozları ile tekrarlanması ile daha detaylı sonuçlar elde edilebilir

Anahtar Kelimeler: Broyler, In ovo besleme, Kuluçka, Kuluçkalık yumurta, Propolis

\section{ABSTRACT}

This study was conducted to determine the effects of propolis extract injection with in ovo feeding method into hatching eggs on incubation success in broiler breeders. A total of 500 Ross 308 broiler hatching eggs were used in the experiment. The study consisted of 5 treatment groups (negative control group, positive control group, first group of 5\% propolis, second groups of propolis of $10 \%$, third groups of propolis of $15 \%$ and 4 replicates of each treatment group. In all groups, the egg weight was distributed to the incubation trays in a similar manner. Injections were applied to the amniotic fluid at a dose of $0.5 \mathrm{ml} / \mathrm{egg}$ per treatment group on day 18 (negative control group -no application- and at a depth of $18 \mathrm{~mm}$ from the small end up). Significant differences were found among the treatment groups for hatchability of fertile eggs, internal and external pipping and total mortality rates $(\mathrm{P}<0.05)$. Differences among treatment groups in terms of dead in trays were statistically insignificant. It was concluded that the propolis source and the application dose of it is a very critical factor as well as correct solvent choose for the success of the study in order to pinpoint the effects of propolis on incubation results. It would be helpful to mention that it is useful to focus on dose studies after identifying similar solvents that would not be harmful to the embryo first.

Key Words: Broiler, In ovo feeding, Incubation, Hatching egg, Propolis

\section{GIRİŞ}

In ovo ilk defa Sharma ve Burmester (1982) tarafından Marek hastalığına karşı hindi yumurtalarında kullanılmıştır. Bunun yanında yapılan bazı çalışmalar, in-ovo D3 vitamini (Hamissou ve ark., 2019), probiotik (Abdulqader vd.,2018), karbonhidratlar (Tako vd.,2004 ), hormonlar (Moore vd., 1994), insülin benzeri Büyüme Faktörü (Kocamis vd., 1999) enjeksiyonunun kuluçka embriyo ölümleri, büyümeleri ve fizyolojik parametreler üzerindeki etkilerini araştırmıştır. Kanatlılarda 
uygun besin maddeleri ile amniyon sivisının desteklenmesi, civcivde önemli bir başlangıç büyümesi gerçekleştirebilir (Anonim, 2015). Araştırmaların yoğunlaştı̆̆ de "propolis" tir (Ghisalberti, 1979; Crane, 1990). Propolis; işçi arıların çeşitli bitkisel kaynaklardan topladıkları maddeleri enzimlerle biyokimyasal değişikliğe uğratıp bir miktar bal mumu karıştırarak oluşturdukları organik bir üründür (Tutkun, 2000; Özkök ve Sorkun, 2001; Özcan vd., 2003). Toplanan propolis miktar1; iklime, mevsime, arıların yaşam dönemlerine göre değişir (Turhan vd., 2015). Propoliste genel olarak \%50-70 bitkisel balzam ve reçine, \%3050 bitkisel mumlar, $\% 5-10$ polen, $\% 10$ esansiyel yağlar ve $\% 5$ organik bileşikler ile minerallerin bulunduğu saptanmıştır (Özkök ve Sorkun, 2001). Propolisin farmakolojik aktiviteye sahip bileşenleri flavanoidler, fenolik asitler ve onların esterleridir. Bu bileşikler bakteriler, virüsler ve mantarlar üzerine çoklu etki göstermektedirler (Lotfy, 2006). Propolis, tıp apiterapi, biyokozmetik alanlarında kullanılmaktadır (Burdock, 1998; Polat ve Koçan, 2006). Yüksek teknoloji antibiyotiklerden farklı olarak, uzun süre propolis kullanımı zararlı bakterilerde direnç oluşturmamaktadır. Şahinler, (2000). Propolisin etanolik etkstraktının, zengin flavanoidler, fenolik bileşikler, steroitler, seskuiterpenler, aminoasitler ve inorganik iz elementler ihtiva ettiği belirtilmektedir (Greenaway vd., 1988). Ayrıca, propolis ekstraktında bulunan Pinobanksin-3-acetate (flavanoid), Pinocembrin, Galangin, Benzil p-coumarate ve kafeik asitin antimikrobiyal etkisinin olduğunu belirlenmiştir (Starzyk vd., 1977). Hayvan denemelerinde propolisin \%1-0.5 sulu çözeltileri solunum hastalıklarında kullanılabileceği belirtilmektedir (Çakır ve Tümen, 1990). Bu çalışmanın amacı, kuluçkanın 18. gününde broyler yumurtalarının amniyon kesesine in ovo besleme yöntemiyle propolis ekstrakt1 enjeksiyonu yapılarak, propolisin kuluçka sonuçları üzerine etkilerini tespit etmektir. Dolayısıyla, propolisin broyler yumurtalarında kuluçka süresi boyunca ve çıkış sonrasında doğal bir sağlık desteği, performans arttırıcı ve erken dönem beslemede iyileştirici katkı maddesi olarak kullanımı ve sektöre olabilecek katkıları ile ilgili sonuçlara ulaşılabilecektir.

\section{MATERYAL ve YÖNTEM}

Kuluçkalık yumurtalar, ticari bir damızlıkçı firmadan temin edilmiştir. Toplam 500 adet Ross 308 broyler ebeveyn yumurtası kullanılmıştır. In ovo besleme solüsyonu olan propolis 
ekstraktlarında, Konya bölgesinden elde edilen propolisler kullanılmıştır. Araştırmada, S.Ü. Ziraat Fakültesi kuluçka laboratuarında bulunan 1 adet 1440 kapasiteli gelişme makinesi ile 1 adet çıkış makinesi (Çimuka) kullanılmıştır. Kuluçkaya konulacak yumurtaların ağırlıklarının ölçülmesinde $0.01 \mathrm{~g}$ hassasiyette elektronik tartı (Radwag) kullanılmıştır. Hazırlanan propolis ekstraktlarının yumurtalara enjeksiyonu için 1250 adet olmak üzere tek kullanımlık $2 \mathrm{ml}$ 21- gauge yeşil enjektörler kullanılmıştır. Araştırmanın deneme deseni; Negatif kontrol grubu (in ovo uygulama yok), Pozitif kontrol grubu (0.5 mL alkol çözeltisi/yumurta), Propolis 1 (P1) grubu $(0.5 \mathrm{~mL} \% 5$ ' lik P1 çözeltisi/yumurta), Propolis 2 (P2) grubu (0.5 mL \%10' luk P2 çözeltisi/yumurta), Propolis 3 (P3) grubu (0.5 mL \%15' lik P3 çözeltisi/ yumurta), olmak üzere beş gruptan oluşmuştur. Yumurtalar kuluçka laboratuarına getirildikten sonra 24 saat süreyle $16-18^{\circ} \mathrm{C}$; $\% 55-60$ nemde depolanmıştır. Gelişim makinesine her muamele grubu için döllü yumurtalar 4 tekerrürlü, yani 25 adet kuluçkalık yumurta alabilen 4 kuluçka tepsisi rasgele yerleştirilmiştir. Her tepsi, her bir muamele grubu için bir tekerrür olarak değerlendirilmiştir. Her muamele grubu için 4 tekerrür ve her tekerrürde 25 adet olmak üzere toplam 100 adet yumurta kullanılmıştır (5 muamele $* 4$ tekerrür $* 25$ adet $=500$ yumurta). Tüm gruplarda yumurta ağırlık ortalaması ve varyasyon katsayısı benzer olacak şekilde, yumurtalar kuluçka tepsilerine dağıtılmıştır. Bütün muamele gruplarındaki yumurtalar ön 1sıtmadan $\left(25^{\circ} \mathrm{C}-12\right.$ saat $)$ geçirildikten sonra, eş zamanlı olarak kuluçka makinesine yüklenmiştir. Kuluçkanın 18. gününden (transfer aşaması) 24 saat önce çıkış makinesi sıcaklığı $37.2^{\circ} \mathrm{C}$ ve \%75 nem oranı sağlanacak şekilde ayarlanarak, yükleme işlemi için makine hazırlanmıştır. Standart kuluçka işlemleri çıkım zamanı sonuna kadar uygulanmıştır.

\section{Propolis Ekstraktının Hazırlanması ve}

\section{Kimyasal Analizi}

In ovo besleme uygulamasinda kullanılacak ham propolis, etanol ekstraksiyon metodu (Seven vd. 2007) ile saflaştırılmış (ekstrakte edilmiş) ve çözelti haline getirilmiştir. Propolis örnekleri araştırmada kullanılana kadar derin dondurucuda muhafaza edilmiştir. Ham propolis derin dondurucuda dondurulduktan sonra porselen havanda ezilerek toz haline getirilmiştir. Toz halindeki propolisten $125 \mathrm{~g}$ alınarak, $1500 \mathrm{ml} \%$ 96' lık ethanol ile ardışık 3 gün boyunca manyetik karıştırıcıda günde 1 
saat süreyle karıştırılmıştır. Elde edilen homojen karışım filtre kağıdı ile süzülmüş ve süzme işlemi üçer kez tekrarlanmıştır. Sonrasında $50^{\circ} \mathrm{C}^{\prime}$ de konsantre edilerek evaporatörde alkolü uçurulmuş ve $60 \mathrm{~g}$ propolis ekstraktı elde edilmiștir. Denemede kullanılan in ovo besleme solüsyonları P1, P2, P3 ve pozitif kontrol grubu için aşağıdaki modele göre hazırlanmıştır. 60 g propolis ekstraktı her bir propolis grubu ( $\mathrm{P} 1$, P2 ve P3) için belli oranlarda tartılarak çözelti formülasyonları oluşturulmuştur. Buna göre; Propolis 1 (P1) grubu (\%5' lik): 5 g propolis ekstrakt1 $+25 \mathrm{ml} \mathrm{saf} \mathrm{su}+70 \mathrm{ml} \% 96$ ' lik ethanol, Propolis 2 (P2) grubu (\%10' luk): 10 g propolis ekstarktı $+20 \mathrm{ml} \mathrm{saf} \mathrm{su}+70 \mathrm{ml} \% 96$ ' lik ethanol, Propolis 3 (P3) grubu (\%15' lik): 15 g propolis ekstraktı $+15 \mathrm{ml}$ saf su $+70 \mathrm{ml} \% 96^{\prime}$ lik ethanol, Pozitif kontrol (alkol) grubu: $20 \mathrm{ml} \mathrm{saf}$ su $+70 \mathrm{ml}$ ethanol, olmak üzere 4 ayrı solüsyon hazırlanmıştır. Kullanılan propolisin kimyasal analiz sonuçları Çizelge 1' de verilmiştir.

\section{In Ovo Besleme Uygulaması}

Uygulama, kuluçkanın 18. gününde in ovo besleme solüsyonlarının. amniyon sıvısı içerisine enjeksiyonu şeklinde gerçekleştirilmiştir. Enjeksiyon için hazırlanan solüsyonlar her bir muamele grubu için $0.5 \mathrm{ml}$ ' lik dozlarda (negatif kontrol grubu (in ovo uygulama yok), pozitif kontrol grubu $(0.5 \mathrm{~mL}$ alkol çözeltisi/ yumurta), propolis 1 (P1) grubu $(0.5 \mathrm{~mL} \mathrm{\% 5}$, lik P1 çözeltisi/yumurta), propolis 2 (P2) grubu (0.5 mL \%10’ luk P2 çözeltisi/yumurta) ve propolis $3(\mathrm{P} 3)$ grubu $\left(0.5 \mathrm{~mL} \% 15^{\prime}\right.$ lik P3 çözeltisi/yumurta) ve tek kullanımlık 2 ml 21-ga iğne kullanılarak yumurtaların küt tarafından 18 mm derinlikte amniyon kesesine uygulanmıştır. Enjeksiyon işlemi tamamlanan yumurtaların küt tarafi $\% 80$ ethanol ile sterilize edilip, yumurta kabuğunda açılan delik parafilm yardımıyla kapatılmıştır.

Çizelge 1. Propolisin kimyasal bileşimi ve etken madde miktarları

\begin{tabular}{|l|l|}
\hline Fenolik Bileşikler & Miktar $(\mathrm{mg} / 100 \mathrm{~g})$ \\
\hline Protokateşuik asit & 1.76 \\
\hline 4-Hidroksibenzoik asit & 5.74 \\
\hline Vanilik asit & 1.75 \\
\hline Kafeik asit & 143.00 \\
\hline p-kumarik asit & 33.37 \\
\hline Ferulik asit & 5.17 \\
\hline Pinocembrin & 24.33 \\
\hline Apigenin & 112.21 \\
\hline Rutin & 0.58 \\
\hline Kaemferol-3-glukozit & 1.62 \\
\hline Kaemferol & 13.09 \\
\hline
\end{tabular}




\section{Verilerin Toplanması}

Çalışma sonunda kabuk-altı ölü, tepside ölü, satılabilir nitelikteki (sağlıklı) civciv sayıları belirlenmiştir. 21. gün tamamlanınca, tepsilerdeki 1skarta ve ölü civcivler ile çıkışı olmayan yumurtalar ayrılmıştır. Kalan yumurtalarda kabuk-altı embriyo analizi yapılarak embriyo ölüm evreleri (erken, geç ve orta dönem, iç ve diş pip) belirlenmiştir. Çıkış saatlerinin belirlenmesi ise; kuluçkanın 06:00, 12:00, 18:00 ve 23:59 saatlerinde ç1kan civcivler sayılarak kontrol altına alınmış, kuluçka süresinin tamamlanmasıyla birlikte ilgili kontrol saatinde çıkan civcivler finalde çıkan toplam civciv sayısına oranlanıp 100 (yüz) ile çarpılarak hesaplanmıştır.

\section{İstatistiki Analizler}

Elde edilen veriler tesadüf parsellerinde tek yönlü varyans analizi (Düzgüneş ve ark., 1987) ve ortalamalar arasındaki farklılıklar Duncan çoklu karşılaştırma testi (Düzgüneş ve ark., 1984) ile belirlenmiştir.. Varyans analizlerinin uygulanmasında ve Duncan çoklu karşılaştırma testlerinde de Minitab (2014) bilgisayar paket programından yararlanılmıştır. Yüzde değerlere istatistik analizinden önce arcsin transformasyonu uygulanmıştır.

\section{BULGULAR}

Propolis ekstraktı enjeksiyonunun, etkilerine ait sonuçlar Çizelge 2' de verilmiştir. Çizelge 2’ de görüldüğü gibi, İP bakımından muamele grupları arasındaki farklılıklar istatistiki olarak önemli bulunmuştur $(\mathrm{P}<0.05)$. İP bakımından gruplar karşılaştırıldığında en düşük değer \% 0 ile NK grubunda, en yüksek değer ise \%11.94 ile P2 grubunda bulunmuştur. Diğer muamele gruplarından PK grubu, P1 grubu ve P3 grubunda ise İP oranları benzer bulunmuştur. $\mathrm{Bu}$ gruplarda İP oranları sırasıyla 4.61, 4.36 ve 6.09 olarak belirlenmiştir. Propolis oranı en yüksek olan P3 ve en düşük olan P1 grubu, P2 grubuna göre İP üzerine daha az olumsuz etki yapmıştır. DP bakımından muamele grupları arasındaki farklılıklar istatistiki olarak önemli bulunmuş olup $(\mathrm{P}<0.01)$, gruplar karşılaştırıldığında en düşük değer NK grubunda, en yüksek değer ise \%19.26 ile P3 grubunda bulunmuştur. Diğer muamele gruplarından PK grubu, P1 grubu ve P2 grubunda ise DP oranları benzer bulunmuştur. Bu gruplarda DP oranları sırasıyla $2.38,4.42$ ve 9.06 olarak belirlenmiştir. Propolis oranı en yüksek olan P3 grubu, diğer muamele gruplarına göre DP üzerinde daha fazla olumsuz etki yapmıştır. TOÖ bakımından muamele grupları arasındaki farklılıklar istatistiki olarak 
önemli bulunmuştur $(\mathrm{P}<0.01)$. TOÖ bakımından gruplar karşılaştırıldığında en düşük değer NK grubunda, en yüksek değer ise \%25.35 ile P3 grubunda bulunmuştur. P3 grubundan sonra en yüksek TOÖ oranı \%21 ile P2 grubunda bulunmuştur. Diğer muamele gruplarından P1 grubu ve PK grubunda ise TOÖ oranları benzer bulunmuştur. Bu gruplarda TOÖ oranları sırasıyla 8.78 ve 6.99 olarak belirlenmiştir. TOÖ üzerine en fazla olumsuz etkiye sahip olan grup propolis oranı en yüksek olan P3 grubu olup, bunu sirasıyla P2, P1 ve PK grupları takip etmiştir. Çalışma sonunda elde edilen TOÖ oranı sonuçlarından, uygulamada kullanılan propolis ekstraktlarının oranı arttıkça toplam ölüm oranının da $\operatorname{arttığı~sonucuna~varılabilir.~}$ Ayrıca muamele gruplarındaki alkol oranlarının da TOÖ’ ü olumsuz etkilediği söylenebilir. TOÖ' de yaşanan durum, anlaşılacağı gibi İP ve DP ortalamalarının bir sonucu olarak gerçekleşmiştir. TÖ bakımından muamele grupları arasındaki farklılıklar istatistiki olarak önemsiz bulunmuştur $(\mathrm{P}>0.05)$. TÖ bakımından muamele grupları arasında en yüksek değer \% 16.60 ile P3 grubunda görülürken, bunu \% 13. 88 ile P2 grubu takip etmiştir. En düşük tepside ölüm oranı ise \% 2.08 ile NK grubu olarak belirlenmiştir. In ovo besleme uygulamas1 yap1lan gruplarda (PK, P1, P2, P3) TÖ oranı NK grubundan daha yüksek olmasına rağmen, aralarındaki fark önemsiz bulunmuştur. ÇG bakımından muamele grupları arasındaki farklılıklar istatistiki olarak önemli bulunmuştur $(\mathrm{P}<0.05)$. ÇG bakımından gruplar karşılaştırıldığında en düşük ortalama değer \% 58.04 ile P3 grubunda, en yüksek değer ise \% 97.91 ile NK grubunda bulunmuştur. NK grubunu \% 85.73 ile PK grubu ve \% 83.62 ile P1 grubu takip etmiştir. P3 grubundan sonra en düşük ÇG oranı \% 65.11 ile P2 grubunda bulunmuştur. Propolis oranı en yüksek olan P3 grubu, diğer muamele gruplarına göre ÇG üzerine daha fazla olumsuz etki gösterirken, P2 grubu da çıkış gücü üzerine önemli düzeyde olumsuz etki yapmıştır. Çıkış gücündeki farklılıkların temel nedeni, ilgili gruplardaki TOÖ oranlarından kaynaklanan farklılıklardır. Çizelge 2' nin incelenmesinden de anlaşılacağı gibi, NK grubunda TOÖ oranı sifir iken, $\mathrm{P} 2$ ve $\mathrm{P} 3$ gruplarında \% 21 ve $\% 25.35$ olarak gerçekleşmiştir.

\section{TARTIŞMA}

Bozbay vd. (2016) yavaş gelişen iki broyler hattında in ovo propolis enjeksiyonunun ve enjeksiyon yerinin kuluçka başarısını 
Çizelge 2. Damızlık broyler yumurtalarına propolis enjeksiyonunun kuluçka sonuçlarna

$$
\text { etkileri, }\left(\%, \bar{X}^{ \pm} S_{\bar{X}} \pm\right)
$$

\begin{tabular}{|l|l|l|l|l|l|}
\hline Grup & İP & DP & TOÖ & TÖ & ÇG \\
\hline NK & $0.0^{\mathrm{b}} \pm 0.0$ & $0.0^{\mathrm{b}} \pm 0.0$ & $0.0^{\mathrm{c}} \pm 0.0$ & $2.08 \pm 1.21$ & $97.91^{\mathrm{a}} \pm 1.21$ \\
\hline PK & $4.61^{\mathrm{ab}} \pm 1.95$ & $2.38^{\mathrm{ab}} \pm 1.38$ & $6.99^{\mathrm{bc}} \pm 3.12$ & $7.27 \pm 2.36$ & $85.73^{\mathrm{ab}} \pm 4.28$ \\
\hline P1 & $4.36^{\mathrm{ab}} \pm 1.60$ & $4.42^{\mathrm{ab}} \pm 2.60$ & $8.78^{\mathrm{abc}} \pm 3.83$ & $7.59 \pm 3.31$ & $83.62^{\mathrm{ab}} \pm 5.75$ \\
\hline P2 & $11.94^{\mathrm{a}} \pm 2.53$ & $9.06^{\mathrm{ab}} \pm 4.19$ & $21.00^{\mathrm{ab}} \pm 4.41$ & $13.88 \pm 7.92$ & $65.11^{\mathrm{bc}} \pm 7.81$ \\
\hline P3 & $6.09^{\mathrm{ab}} \pm 3.97$ & $19.26^{\mathrm{a}} \pm 5.27$ & $25.35^{\mathrm{a}} \pm 2.85$ & $16.60 \pm 4.33$ & $58.04^{\mathrm{c}} \pm 6.48$ \\
\hline P & $<0.05$ & $<0.01$ & $<0.01$ & $>0.05$ & $<0.05$ \\
\hline
\end{tabular}

*İP: İç pip, DP: Dış pip, TOÖ: Toplam ölüm, TÖ: Tepside ölü, ÇG: Çıkış gücü

**NK: Negatif kontrol , PK: Pozitif kontrol , P1: Propolis 1, P2: Propolis 2, P3: Propolis 3

***P: Önem düzeyi, a-c: Aynı sütunda farklı harflerle gösterilen ortalamalar arasındaki farklılıklar önemlidir.

etilemediğini ifade etmişlerdir. Coşkun ve ark. (2014) tarafindan polen ekstraktının etkisinin araştırıldığı çalışmada, kuluçka randımanları kontrol, polen ekstraktı ve negatif kontrol gruplarında sirasıyla \% 89.1 , 82.3, 73.1 olarak bulunmuştur. Öte yandan İpek ve ark. (2004), broyler ebeveynlerine ait kuluçkalık yumurtalarında farklı oranlarda glikoz (5, 10, 15 mg) enjeksiyonunun, düşük seviyeli uygulamanın çıkış gücünü artırdığ1 bildirmişlerdir. Benzer şekilde Robel (2002), hindi yumurtalarına biyotin, folik asit ve pridoksin enjeksiyonunun çıkış gücünü artırdığını bildirmiştir. Mevcut çalışmamızda ise, çıkış gücü bakımından muamele grupları arasında istatistiki olarak önemli farklılıklar bulunmuş $(\mathrm{P}<0.05)$ ve propolis oranı yüksek olan gruplar (P2, P3), çık1ş gücüne önemli düzeyde olumsuz etki yapmışlardır. Dolayısıyla, çıkış gücüne ilişkin elde ettiğimiz bulgular bahsedilen çalışmaların sonuçları ile benzerlik göstermemektedir. Ancak Uni vd. (2003)’ nın, kuluçkanın 0. ve 7. günlerinde yumurta sarı kesesi ve hava boşluğuna amino asit enjeksiyonunun ç1k1ş gücünü önemli derecede düşürdüğüne yönelik ifadeleri mevcut çalışmamız ile kısmen uyumludur. Mevcut kaynaklarda kuluçka sonuçları üzerine in ovo propolis enjeksiyonunun etkilerine ait çok az sayıda literatür yer almaktadır. $\mathrm{Bu}$ nedenle literatür karşılaştırmasında, in ovo propolis enjeksiyonu yanında in ovo besleme uygulamalarının kuluçka 
sonuçları üzerine etkileri ile ilgili araştırma sonuçları da değerlendirilmiştir. Buna göre, Uni vd. (2005)’ nın, kuluçkanın 17. gününden sonra embriyoların amniyon sıvılarına karbonhidrat ilavesi yaptıkları çalışmanın sonunda, in ovo besleme uygulanan grupta civciv çı1şş ağırlıklarının kontrol grubuna göre \% 5-6 oranında daha yüksek olduğunu bildirmişlerdir. Kadam vd. (2008) tarafindan yapılan bir araştırmada, broyler yumurtalarına kuluçkanın 14. gününde threonine amino asit enjeksiyonu ile civciv ağırlığında yumurta ağırlığına oranla \% 1.6 artış olduğu belirlenmiştir. Bir başka çalışmada, Elibol vd. (2001), kuluçka sırasında ağır yumurtalara askorbik asit enjeksiyonunun kuluçka özellikleri üzerine etkisini belirlemek amacıyla yaptıkları çalışmada, askorbik asit enjekte edilen grupta son dönem embriyo ölümlerinin tuzlu su grubuna $(\mathrm{P}<0.01)$ ve kontrol grubuna $(\mathrm{P}<0.05)$ göre önemli seviyede düşük olduğu tespit edilmiştir. Bunun yanında tuzlu su enjekte edilen grupta çıkış gücü oranı daha düşük olup, fark istatistiki olarak önemli bulunmuştur $(\mathrm{P}<0.05)$.

\section{SONUÇ ve ÖNERILER}

Çalışmada uygulanan muamelelerin kuluçka sonuçlarından ÇG, İP, DP ve TOÖ oranlarını istatistiki olarak olumsuz etkilediği görülmüştür. TÖ oranı bakımından muamele grupları arasındaki farklılıklar ise istatistiki olarak önemsiz bulunmuştur. Her ne kadar TÖ oranı bakımından gruplar arası farklılıklar önemsiz bulunmuş olsa da, ortaya çıkan farklar ticari açıdan önemlidir. ÇG bakımından elde edilen sonuçlardan, yüksek propolis ekstraktı oranlarının çıkış gücünü azalttığı, düşük oranların ise çıkış gücünü arttırması nedeniyle, broyler damızlık yumurtalarına uygulanan propolis ekstraktlarının düşük oranlarının (\%5' lik ve daha az) daha güvenle kullanılabileceği sonucuna varılmıştır. Ancak kullanılan çözücülerin (ki burada ethanol) olumsuz etkilerinin propolis kullanımının avantajını gölgelediği kanaati oluşmuştur. Çalışma verilerine dayanarak, kuluçkalık yumurtaların propolisle muamele edilmesinde, formülasyonlarda (dozajlama) yapılacak değişiklikler kadar, daha öncede değinildiği gibi, farklı oranlarda propolis ekstraktları kadar farklı çözücülerin (eter, kloroform, aseton, su vb.) kullanılması da kuluçka sonuçlarını iyileştirebilir. 


\section{KAYNAKLAR}

Abdulqader, A. F., Aygün, A., Maman, A.H., Olgun, O., 2018. The effect of inovoinjection of Lactobacilla Rhamnosus on hatching traits and growth parameters of quails. Selcuk Journal of Agriculture and Food Sciences, 32: 1748 .

Anonim. 2015. Yumurta İçi (In-ovo) Besleme Kanatlı Üretimini İyileştirebilir. (http:// www.kanatlibilgi.com), (Erişim Tarihi: 10.03.2015).

Bozbay, C. K., Konanç, N., Ocak, N., Öztürk, E., 2016. Yumurta içi (in ovo) propolis enjeksiyonunun ve enjeksiyon yerinin kuluçka randımanı, civciv çıkış ağırlığı ve yaşama gücüne etkileri. Türkiye Tarımsal Araştırmalar Dergisi, 3: 48-54.

Burdock, G. A., 1998. Review of the biological properties and toxicity of bee propolis. Food Chemistry Toxicology, 36: 347-363.

Coşkun, İ., Çayan, H., Yıılmaz, H., Ö., Taskın, A., Tahtabiçen, E., Samli, H.E., 2014. Effects of in ovo pollen extrakt injection to fertilite broiler egss on hatchability and subsequent chick weight. Türk Tarım ve Doğa Bilimleri Dergisi 4: 485-489.

Crane, E. 1990. Bees and Beekeeping Science Practice and World Resources. Heinemann Professional Publishing Ltd. Oxford, 640 S.

Çakır, H., Tümen, G., Balıkesir Yöresi Ballarının
Antimikrobiyal ve Antifungal Etkileri. X.

Ulusal Biyoloji Kongresi, Erzurum, 210, 1990.

Düzgüneş, O., Kesici, T., Gürbüz, F., 1984. İstatistik Metotları-I, Ankara Üniversitesi Ziraat Fakültesi Yayınları, No:861, Ders kitab1 no: 229, Ankara, 218 s.

Düzgüneş, O., Kesici, T., Kavuncu, O., Gürbüz, F., 1987. Araştırma ve Deneme Metotları (İstatistik metotlar1-II), Ankara Üniversitesi Ziraat Fakültesi Yayınları, No:1021, Ders kitab1 no: 295, 381s.

Elibol, O., Türkoğlu, M., Akan, M., Erol, H., 2001. İnkübasyon sırasında ağır yumurtalara askorbik asit enjeksiyonunun kuluçka özelliklerine etkisi. Turkish Journal of Veterinary and Animal Sciences, 25: $245-248$.

Ghisalberti E. L. 1979. Propolis: A reiew, Bee World, 60: 59-84.

Greenaway, W., T. Scaysbrook, Whatley., F.R., 1988. Composition of propolis on Oxfordshire, UK and its relation to poplar bud exudate, Zeitschrift für Naturforsch, 43: 301-305.

Hamissou Maman A, Aygün A, Yıldırım. I , Alsadoon M ., 2019. Effects of in-ovo injection of D3 vitamin on hatchability and supply organ weights in quail hatching eggs. Bahri Dağdaş hayvancılık Araştırma Dergisi, 1: 21-27. 
İpek, A., Sahan, U., Y1lmaz, B., 2004. The effect of in ovo ascorbic acid and glucose injection in broiler breeder eggs on hatchability and chick weight, Archiv für Geflügelkunde 68 (3): 132-135.

Kadam, M. M., Bhanja, S. K., Mandal, A. B., Thakur, R., Vasan, P., Bhattacharyya, A., Tyagi, J. S., 2008. Effect of in ovo threonine supplementation on early growth, immunological responses and digestive enzyme activities in broiler chickens, British Poultry Science 49: 736741.

Kocamis,H., Yeni, Y., Kirkpatrick-Keller, D., Killefer, J, 1999. Postnatal growth of broilers in response to inovoadministration of chicken growth hormone, Poultry Science 78: 1219-26.

Lotfy, M. 2006. Biologiacal activity of bee propolis in health and disease. Asian Pacific Journal of Cancer Prevention, 7: 22-31.

Minitab 2014. Minitab for windows, Release 16., Minitab Inc., New-York, ABD.

Moore, R. W., Dean, C.E., Hargis, P.S., Hargis, B.M., 1994. Effects of in ovohormone administration at day eighteen of embryogenesis on posthatch growth of broilers. Journal of Applied Poultry Research 3: 31-9.
Özcan, M., Ceylan, D.A., Unver, A., Yetişir, R., 2003. Türkiye'nin çeşitli bölgelerinden sağlanan polen ve propolis ekstraktlarının antifungal etkisi. Uludag Bee Journal 3: 27-34.

Özkök, A., Sorkun, K., 2001. Apiterapide kullanılan önemli arı ürünlerinden: bal, polen ve propolis. Teknik Arıcılık, 72: 4-10.

Polat, G., Koçan. D., 2006. Propolis ve antimikrobiyel etkisi. Türkiye 9. Gıda Kongresi, 24-26 Mayıs, Bolu.

Robel, E. J., 2002. Assessment of dietary and egg injected d-biotin, pyridoxine, and folic acid on turkey hatchability: Folic acid and poult weight. World's Poultry Science Journal, 58: 305-315.

Seven, İ., Aksu, T., Seven, P.T., 2007. Propolis ve hayvan beslemede kullanımı. Yüzüncü Y1l Üniversitesi Veterinerlik Fakültesi Dergisi, 18: 79-84.

Sharma,J., Burmester, B., 1982. Resistance of marek's disease at hatching in chickens vaccinated as embryos with the turkey herpesvirus. Avian Diseases 134-49.

Starzyk, J., Scheller, S., Szaflarski, Moskwa, J., M., Stojko, A., 1977. Biological properties and clinical application of propolis. Azneim-Forsch Drug Research 27: 11981199. 
Şahinler, N., 2000. Arı ürünleri ve insan sağlığı açısından önemi. Mustafa Kemal Üniversitesi Ziraat Fakültesi Dergisi, 5: 139-148.

Tako, E., Ferket, P., Uni, Z., 2004. Effects of in ovofeeding of carbohydrates and beta-hydroxy-beta-methylbutyrate on the development of chicken intestine. Poultry Science 83: 2023-2028.

Turhan, M., Söğüt, B., İnci, H., 2015. Bal arılarında propolis toplama ve hijyen davranış1. 9. Ulusal Zootekni Bilim Kongresi, 3-5 Eylül, Konya, 569.

Tutkun, E., 2000, Teknik Arıcılık El Kitab1, ISBN 975-93747-2000, Türkiye Kalkınma Vakfi, Yayın No:6, Ankara.

Uni, Z., Ferket, P. R., Tako, E., Kedar, O., 2005. In ovo feeding improves energy status of late-term chicken embryos. Poultry Science 84: 764-770.

Uni, Z., Smirnov, A., Sklan, D., 2003. Pre- and posthatch development of goblet cells in the broiler small intestine: Effect of delayed access to feed. Poultry Science 82: 320-327. 